\title{
ESTIMATIVA DOS COMPONENTES DE VARIÂNCIA E HERDABILIDADE PARA FORMATO DE FRUTO EM PORONGO - Lagenaria siceraria (Mói.) Standl
}

\author{
VARIANCE COMPONENTS AND HERITABILITY ESTIMATION FOR FRUIT SHAPE IN \\ BOTTLEGOURD - Lagenaria siceraria (Mói.) Standl
}

\author{
Dilson António Bisognin ${ }^{1}$ Lindolfo Storck ${ }^{2}$
}

RESUMO

O conhecimento das estimativas dos componentes de variância e da herdabilidade de importantes características agronómicas, como é o caso do formato de fruto em porongo, é fundamental para definir as estratégias de seleção e estimar o ganho genético. Progênies de meio-irmãos de porongo foram avaliadas com os objetivos de: (i) estimar os componentes de variância e de covariância; (ii) estimar a herdabilidade do caráter formato de fruto $e$; (iii) delinear algumas inferências em relação ao ganho genético obtido com seleçâo de frutos individuais em porongo. Componentes de variância genética significativos foram obtidos para diâmetro maior e do pescoço da cuia $e$, ambiental, para formato de fruto. A estimativa de herdabilidade para o caráter formato de fruto, para seleçâo em nível de frutos individuais, foi intermediária (0,36), e moderadamente alta para médias de famílias (0,53). Seleçâo massal entre médias ou dentro de famílias de meio-irmãos é o método de melhoramento mais apropriado para seleçâo do caráter formato de fruto em porongo.

Palavras-chave: herdabilidade, variância genética, seleçâo, porongo.

\section{SUMMARY}

Variance components and heritability estimation of agronomic traits, such as fruit shape in bottlegourd are very importam to define selection strategies and to estimate selection gain. Nine progénies of half-sib families were evaluated aiming to estimate variance and covariance components, the heritability of fruit shape and to understand the origin of the genetic gain with mass selection in bottlegourd fruits. Significative estimates were found for genetic variance of large diameter and neck diameter $o$ $f$ the "cuia" (commercial part of the bottlegourd) and for environmental variance of fruit shape. Heritability estimate for fruit shape selection based on fruit was moderately (0.36) and moderately high for family mean (0.53). Mass selection based upon mean population performance or within populations is the breeding method more appropriate for improvement of fruit shape in bottlegourd.

Key words: heritability, genetic variance, selection, bottlegourd.

\section{INTRODUÇÃO}

Para o cultivo do porongo - Lagenaria siceraria (Mói.) Standl -, n a região de Santa Maria, RS, são utilizadas sementes oriundas de frutos selecionados, na própria lavoura comercial. Os frutos são selecionados basicamente pelo tamanho e o formato, sem nenhuma atribuição à planta, ou seja, é uma seleçâo fenotípica de frutos individuais. Também, não se conhece a origem das populações de porongo utilizadas na região, sendo que as mesmas apresentam características fenotípicas muito similares, sugerindo origem de uma ou poucas populações e selecionadas para as diferentes necessidades ou critérios dos produtores. BISOGNIN \& MARCHEZAN (1988) avaliaram dez populações de porongo utilizadas na Região e verificaram que as diferenças em produtividade observadas entre as mesmas foram devidas ao maior percentual de frutos industrializáveis, ou seja, um resultado do ganho de seleçâo baseada no formato dos frutos destinados à produção de sementes.

Muito pouco se conhece em termos da genética do formato de fruto em porongo. PATHAK

\footnotetext{
${ }^{1}$ Engenheiro Agrônomo, Mestre, Professor do Departamento de Fitotecnia, Universidade Federal de Santa Maria (UFSM), 97105-900, Santa Maria - RS. Doutorando na Michigan University - USA e Bolsista CNPq. E-mail: dilsonb@ccr.ufsm.br. Autor para correspondência.

${ }^{2}$ Engenheiro Agrônomo, Doutor, Professor Títular do Departamento de Fitotecnia, UFSM. Bolsista CNPq. Recebido para publicação em 19.04.99. Aprovado em 20.10.99
} 
\& SINGH (1950) estudaram a genética do formato (garrafa, taco, redondo e intermediários) e coloração (verde e branco). $\mathrm{O}$ cruzamento entre frutos de garrafa com pescoço (GP - tipo industrial para cuia) e garrafa sem pescoço (GS) resultou na segregação de dois pares de genes na proporção de 9 GS: 3 taco: 4 GP. O cruzamento entre fruto redondo e taco segregou para um par de genes na proporção de 1 redondo:2 funil:1 taco. Para coloração do fruto, os mesmos autores encontraram dominância total de um gene segregando na proporção de 3 verde: 1 branco. TYAGI (1976) verificou que fruto com formato de disco é dominante sobre redondo e garrafa, sendo este caráter governado por um par de genes. Essas descobertas explicam, em parte, a grande variabilidade para formato de fruto encontrada nas populações de porongo e a baixa percentagem de frutos industrializáveis, justificando uma seleção criteriosa para esse caráter.

O melhoramento genético de qualquer característica fenotípica requer o conhecimento prévio de sua herdabilidade, sendo que poucos estudos foram realizados em porongo, dificultando a definição de estratégias de seleção ou a interpretação de ganho genético. PRASAD \& PRASAD (1979) estudaram a herdabilidade e o ganho genético em 15 características quantitativas em uma coleção de 40 cultivares de porongo. Altas estimativas de herdabilidade e de ganho genético foram obtidas para todas características estudadas. Em pepino, OWENS et al. (1985) utilizaram o método do retrocruzamento de linhas endogâmicas para o estudo da herdabilidade e obtiveram uma estimativa moderadamente alta para comprimento de fruto. SMITH et al. (1978) encontraram alta estimativa de herdabilidade para a relação comprimento/diâmetro de fruto.

Os objetivos deste trabalho foram: (i) estimar os componentes de variância e de covariância; (ii) estimar a herdabilidade do caráter formato de fruto e; (iii) delinear algumas inferências em relação ao ganho genético obtido com seleção de frutos individuais em porongo.

\section{MATERIAL E MÉTODOS}

Nove linhagens de porongo oriundas de uma ou duas gerações de autofecundação, seguida de seleção para o caráter formato de fruto, foram intercruzadas ao acaso na safra 1995/96. As sementes produzidas por um fruto tomado ao acaso de cada linha constituíram cada progénie, com grau de parentesco (sementes dentro de fruto) igual a meio-irmãos. $\mathrm{O}$ experimento com as nove progénies foi conduzido no campo experimental do Departamento de Fitotecnia - UFSM, em quatro repetições arranjadas segundo o delineamento de blocos ao acaso. A semeadura foi efetuada no dia 29 de outubro de 1996. A parcela foi constituída por uma cova com duas plantas, sendo as covas espaçadas em 1,5m entre e dentro das fileiras. Todos os frutos produzidos em cada planta foram colhidos e os dados anotados separadamente.

Para cada fruto colhido foram avaliados o diâmetro maior externo da cuia (DG) e o diâmetro menor externo da cuia ou pescoço (DP). Avaliou-se também a relação $\mathrm{R}=\mathrm{DP} / \mathrm{DG}$. Quanto mais próximo de 0,8 for o valor de $\mathrm{R}$, maior é o valor comercial da cuia. Assim, a expressão $\mathrm{G}=125^{*}[0,8$-Absoluto (R$0,8)$ ] estima essa qualidade do formato da cuia.

Para a análise dos dados, considerou-se $\mathrm{J}$ = 4 blocos, $\mathrm{I}=9$ progénies, $\mathrm{K}=2$ plantas/parcela e $\mathrm{n}$ = número variado de frutos/planta. $\mathrm{O}$ modelo matemático foi caracterizado por: $Y_{\mathrm{ijkl}}=\mathrm{m}+\mathrm{b}_{\mathrm{j}}+\mathrm{t}_{\mathrm{i}}$ $+\mathrm{e}_{\mathrm{ij}}+\mathrm{d}_{\mathrm{k}(\mathrm{ij})}+\mathrm{u}_{\mathrm{l}(\mathrm{ijk})}$ onde: $\mathrm{Y}_{\mathrm{ijk}}$ é o valor observado no fruto 1 da planta $\mathrm{k}$ da progénie $\mathrm{i}$ do bloco $\mathrm{j} ; \mathrm{m}=$ média; $b_{j}=$ efeito aleatório de bloco $j ; t_{i}=$ efeito aleatório de progénie ${ }_{\mathrm{i}} ; \mathrm{e}_{\mathrm{ij}}=$ efeito aleatório de erro experimental $\mathrm{ij} ; \mathrm{d}_{\mathrm{k}(\mathrm{ij})}=$ efeito aleatório da planta $\mathrm{k}$ dentro da parcela ij e $\mathrm{u}_{\mathrm{l}(\mathrm{ijk})}=$ efeito aleatório do fruto 1 dentro da planta ijk.

Para a análise de variância (Tabela 1), o número de frutos/planta (n) foi estimado pela média harmónica, considerando as quatro repetições. Adaptando as expressões de VENCOVSKY \&

Tabela 1 - Análise de variância com definição dos graus de liberdade (GL) das esperanças matemáticas dos quadrados médios (QM).

$\begin{array}{llcc}\text { Causas de Variação } & \text { GL* } & \text { QM } & \text { E(QM) } \\ & & & \\ \text { Blocos (b) } & \mathrm{J}-1 & \cdots & \\ \text { Progênies (t) } & \mathrm{I}-1 & \mathrm{Q}_{1} & \sigma^{2}+n \sigma_{d}^{2}+n K \sigma_{e}^{2}+n J K \sigma_{t}^{2} \\ \text { Erro entre parcelas (e) } & (\mathrm{I}-1)(\mathrm{J}-1) & \mathrm{Q}_{2} & \sigma^{2}+n \sigma_{d}^{2}+n K \sigma_{e}^{2} \\ \text { Erro entre plantas (d) } & \mathrm{J}(\mathrm{K}-1) & \mathrm{Q}_{3} & \sigma^{2}+n \sigma_{d}^{2} \\ \text { Erro entre frutos (u) } & \mathrm{IJK}(\mathrm{n}-1) & \mathrm{Q}_{4} & \sigma^{2}\end{array}$

* $\mathrm{J}=$ número de blocos; $\mathrm{I}$ = número de progênies; $\mathrm{K}$ = número de plantas/parcela; $\mathrm{n}=$ média harmônica do número de frutos/planta. 
BARRIGA (1992) para o presente caso, foram obtidas as estimativas dos seguintes componentes de variância: estimativa da variância entre frutos $=\sigma^{2}=$ Q4; estimativa da variância entre plantas $=\sigma_{\mathrm{d}}{ }^{2}=\left(\mathrm{Q}_{3^{-}}\right.$$\left.\mathrm{Q}_{4}\right) / \mathrm{n}$; estimativa da variância entre parcelas $=\sigma_{\mathrm{e}}^{2}=$ $(\mathrm{Q} 2-\mathrm{Q} 3) / \mathrm{nk}$ e; estimativa da variância entre progénies $=\sigma_{\mathrm{t}}^{2}=(\mathrm{Q} 1-\mathrm{Q} 2) / \mathrm{nJK}$ em que Q1, Q2, Q3 e Q4 são os quadrados médios definidos na tabela $\mathrm{l}$.

Com as estimativas dos componentes de variância, foi estimada a herdabilidade $h_{i}^{2}=4 \sigma_{\mathrm{t}}^{2}$ / $\left(\sigma^{2}+<\sigma_{d}^{2}+\sigma_{e}^{2}+<\sigma_{t}^{2}\right)$ para a seleção em nível de frutos individuais $h_{\mathrm{m}}{ }^{2}=\sigma_{\mathrm{t}}{ }^{2}, /\left(\sigma^{2} / \mathrm{nJK}+\left(\sigma_{\mathrm{d}}{ }^{2} / \mathrm{JK}+\right.\right.$ $\sigma_{\mathrm{e}}^{2} / \mathrm{J}+\sigma_{\mathrm{t}}^{2}$ ) para a seleção entre médias de famílias de meio-irmãos; $h_{d}^{2}=3 \sigma_{t}^{2} / \sigma_{d}^{2}$ para a seleção massal dentro de famílias de meio-irmãos.

Foram obtidas as seguintes estimativas de componentes de covariância para os caracteres x e y: estimativa da covariância entre frutos $=\sigma_{\mathrm{xy}}=$ PM4$=$ estimativa da covariância entre plantas $=\sigma_{\mathrm{dxy}}$ $=(\mathrm{PM} 3-\mathrm{PM} 4) / \mathrm{n} ;$ estimativa da covariância entre parcelas $=\sigma_{\text {exy }}=(\mathrm{PM} 2-\mathrm{PM} 3) / \mathrm{nK}$; estimativa da covariância entre progénies $=\sigma_{\mathrm{txy}}=(\mathrm{PM} 1$ $\mathrm{PM}$ )/nJK. Os valores de PM1, PM2, PM3 e PM4 são os produtos médios definidos na tabela 2 .

As correlações (r): $r_{t x y}=\sigma_{t x y} /\left(\sigma_{t x}+\sigma_{t y}\right)$ para progénies; $r_{e x y}=\sigma_{e x y} /\left(\sigma_{e x}+\sigma_{e y}\right.$ para parcelas; $\mathrm{r}_{\mathrm{dxy}}=\sigma_{\mathrm{dxy}} /\left(\sigma_{\mathrm{dx}}+\sigma_{\mathrm{dy}}\right)$ para plantas e; $\mathrm{r}_{\mathrm{xy}}=\sigma_{\mathrm{xy}} /\left(\sigma_{\mathrm{dx}}\right.$ $+\sigma_{\mathrm{dy}}$ ) para frutos, foram estimadas para as variáveis $\mathrm{x}=\mathrm{DG}$ e $\mathrm{y}=\mathrm{G}$, usando as estimativas dos componentes de variância e covariância.

\section{RESULTADOS E DISCUSSÃO}

Os componentes de variância genética (entre progénies e entre plantas) foram significativos para as características DG e DP e não significativos para formato de fruto ou índice de qualidade, representado pelo grau da relação entre DG e DP (G) (Tabela 3). O fato de que o componente de variância ambiental foi significativo para formato de fruto demonstra que a variabilidade genética para este caráter é muito restrita entre as nove progénies. Isso era esperado, pois as progénies foram originadas de cruzamentos entre linhas submetidas à seleção para formato de fruto. Os demais componentes de variância não foram significativos.

A caracterização de frutos industrializáveis não se restringe apenas ao formato (garrafa com pescoço), mas também a atributos como tamanho da cuia e espessura do casco, sendo que o ambiente é um importante componente do fenótipo dessas características. O tamanho de fruto e a espessura de casco apresentam uma relação inversa com a densidade de semeadura (BISOGNIN et al., 1992). Também, a senescência natural das plantas, que interrompe o crescimento dos frutos, resulta em frutos menores e de menor espessura de casco (BISOGNIN et al., 1997). Os resultados obtidos neste trabalho demostram que a variância ambiental (erro entre parcelas) foi o único componente de variância significativo para formato de fruto, novamente indicando o ambiente como um componente fenotípico importante.

Alta estimativa de herdabilidade para seleção em nível de frutos individuais foi obtida para a característica DP $(0,88)$ e baixa para DG $(0,33)$, resultando em baixa estimativa de herdabilidade para o formato de fruto $(0,36)$ (Tabela 4). Alta herdabilidade para DG é importante pelo fato de que DG está diretamente relacionado com o tamanho de cuia, outra importante característica comercial, indicando que seleção para tamanho de cuia pode ser efetuado em nível de fruto. Considerando que os produtores normalmente praticam seleção massal de frutos individuais e que este caráter apresenta média herdabilidade, limitando o ganho genético, esses resultados estão de acordo com a observação de que o formato de fruto foi $o$ fator determinante para a reduzida
* $\mathrm{J}=$ número de blocos; $\mathrm{I}$ = número de progênies; $\mathrm{K}=$ número de plantas/parcela; $\mathbf{n}=$ média harmônica do número de frutos/planta. 
Tabela 3 - Análise da variância para diâmetro maior (DG), diâmetro menor da cuia (DP) e formato de fruto $(\mathrm{G})$ de porongo e produto médio (PM) entre DG e G.

Quadrados Médios

\begin{tabular}{|c|c|c|c|c|c|}
\hline Blocos & 3 & 5,22 & 16,29 & 76,32 & 9,67 \\
\hline Progênies & 8 & $18,78^{*}$ & $53,91 *$ & 666,17 & 29,59 \\
\hline Erro entre parcelas & 24 & 8,21 & 13,58 & $314,48^{*}$ & 20,96 \\
\hline Erro entre plantas & 36 & $11,61^{*}$ & $14,32 *$ & 129,46 & 11,35 \\
\hline Erro entre frutos & 324 & 1,20 & 1,44 & 88,55 & $-0,91$ \\
\hline Média & $\cdots$ & 9,18 & 7,08 & 82,98 & --- \\
\hline Coef. Variação (\%) & $-\cdots$ & 11,93 & 16,97 & 11,34 & -- \\
\hline
\end{tabular}

* Variância significativa em nível de 0,05 de probabilidade de erro.

média da percentagem de frutos industrializáveis encontrada por BISOGNIN \& MARCHEZAN (1988). A redução da percentagem de frutos industrializáveis também pode ser explicada pelo tipo de herança do caráter, onde o formato que qualifica o fruto para indústria segrega na proporção de 4 frutos com formato garrafa com pescoço para 16 com outros formatos (PATHAK \& SINGH, 1950) ou 1 fruto com formato garrafa com pescoço para 4 com outros formatos (TYAGI, 1976), dependendo do formato envolvido no cruzamento. Estimativa de herdabilidade para o caráter formato de fruto foi modestamente alta $(0,53)$ para seleção entre média de famílias e alta $(1,0)$ para seleção dentro de famílias de meio-irmãos. PRASAD \& PRASAD (1979) reportaram, na média de dois anos, altas estimativas de herdabilidade para outras características de fruto em porongo como número de frutos por planta $(0,88)$, peso de fruto $(0,91)$, comprimento de fruto $(0,98)$ e espessura de casco $(0,97)$.

O conjunto das estimativas de herdabilidade mostra que o formato de fruto em porongo apresenta um componente ambiental importante, justificando o uso de seleção entre e dentro de famílias ou seleção com teste de progénie. As estimativas de herdabilidade para seleção entre e dentro de famílias de meio-irmãos sugerem que o formato de fruto é governado, principalmente, por genes de ação aditiva e que a seleção baseada em plantas individuais é mais efetiva do que o uso de cruzamentos para explorar $\mathrm{o}$ vigor híbrido. Em outras palavras, sugere a seleção como sendo o método de melhoramento mais indicado, ao invés da hibridação, para o melhoramento do caráter formato de fruto em porongo. Também é importante considerar que estimativas de variância obtidas a partir de populações aparentadas geneticamente, como é o caso neste experimento, apresentam similar variância genética, fazendo com que a seleção deva ser baseada no desempenho médio das populações e não dos indivíduos (DUDLEY \& MOLL, 1969).

Esses resultados indicam que a seleção para formato de fruto não pode ser efetuada indiretamente, baseada no DG da cuia em nível de progénie. Por outro lado, a relativamente alta correlação obtida para planta $(0,59)$ indica que seleção indireta para formato de fruto pode ser efetuada entre plantas de uma mesma progénie de meio-irmãos com base no DG. Essa relação positiva tem importância limitada, pois os frutos perdem seu valor comercial a partir de determinado tamanho, independente do seu formato. $\mathrm{O}$ fato de não ter sido encontrada correia- cão entre DG da cuia e formato de fruto $(-0,09)$, que corresponde a correlação ambiental, indica que a

Tabela 4 - Estimativas dos componentes de variância e herdabilidade para diâmetro maior (DG) e menor (DP) da cuia e formato de fruto $(G)$ de porongo e correlação entre $D G$ e $G$.

\begin{tabular}{lcccc}
\hline Estimativa* & DG & DP & G & Corr(DG;G) \\
\hline Progênies $\left(\hat{\sigma}_{t}^{2}\right)$ & 0,380 & 1,449 & 12,632 & 0,141 \\
Parcelas $\left(\hat{\sigma}_{e}^{2}\right)$ & 0,000 & 0,000 & 26,583 &.-- \\
Plantas $\left(\hat{\sigma}_{d}^{2}\right)$ & 2,991 & 3,701 & 11,756 & 0,594 \\
Frutos $\left(\hat{\sigma}^{2}\right)$ & 1,200 & 1,440 & 88,550 & $-0,088$ \\
$h_{i}^{2}$ & 0,332 & 0,879 & 0,362 & $-\cdots$ \\
$h_{m}^{2}$ & 0,477 & 0,738 & 0,528 & $\cdots$ \\
$h_{d}^{2}$ & 0,381 & 1 & 1 & $-\cdots$ \\
\hline
\end{tabular}

$* h_{i}^{2}=$ herdabilidade estimada para seleção entre frutos individuais;

$h_{m}^{2}=$ herdabilidade para médias de famílias;

$h_{d}^{2}=$ herdabilidade para seleção dentro de famílias.

Ciência Rural, v. 30, n. 4, 2000. 
seleção para formato de fruto pode ser executada entre frutos, usando o DG da cuia como parâmetro de seleção, porém com menor ganho genético devido à herdabilidade ser média baixa $(0,36)$.

\section{CONCLUSÃO}

Seleção massal entre médias ou dentro de famílias de meio-irmãos é o método de melhoramento mais apropriado para seleção do caráter formato de fruto em porongo.

\section{REFERÊNCIAS BIBLIOGRÁFICAS}

BISOGNIN, D.A., MARCHEZAN, E. Avaliação de algumas populações de porongo - Lagenaria siceraria (Mói.) Standl. cultivadas na região de Santa Maria, RS. Ciência Rural, Santa Maria, v.18, n.3-4, p.201-207,1988.

BISOGNDM, D.A., MARCHEZAN, E., AUDE, M.I.S. Densidade de semeadura e produtividade do porongo. Ciência Rural, Santa Maria, v.22, n.1, p.15-19,1992.

BISOGNIN, D.A., MENEZES, N.L. de, BELLÉ, R.A., et al. Efeito do tamanho de fruto e do método de extração na qualidade fisiológica de sementes de porongo. Ciência Rural, Santa Maria, v.27, n.1, p.13-19,1997.
DUDLEY, J.W., MOLL, R.H. Interpretation and use of estimates of heritability and genetic variances in plant breeding. Crop Science, Madison, v.9, n.3, p.257-262,1969.

OWENS, K., DUDLEY W., BLISS, EA., et al. Genetic analysis of fruit lenght and weight in two cucumber populations using the inbred backcross Une method. Journal of American Society of Horticultural Science, v.1110, n.3, p.431-436, 1985 .

PATHAK, G.N., SDMGH, B. enetical studies in Lagenaria leucantha (Duchs.) rusby - Lagenaria vulgaris Ser. Indian Journal of Genetics and Plant Breeding, v.10, p.28-35, 1950 .

PRASAD, R., PRASAD, A. A note on heritability and genetic advance in bottlegourd - Lagenaria siceraria (Mói.) Standl. Indian Journal of Horticulture, v.36, n.4, p.446-448,1979.

SMITH, O.S., LOWER, R.L., MOLL, R.H. Estimates of heritabilities and variance components in pickling cucumber. Journal of American Society of Horticultural Science, v.103,n.2,p.222-225,1978.

TYAGI, I.D. Inheritance of some qualitative characters in bottlegourd Lagenaria siceraria (Mói.) Standl. Indian Journal of Horticulture, v.33, n.l, p.79-82. 1976.

VENCOVSKY, R., BARRIGA, P. Genética biométrica no fitoinelhoramento. Ribeirão Preto : Revista Brasileira de Genética, 1992. 496p.

Ciência Rural, v. 30, n. 4, 2000. 